\title{
A Girl with Life Threatening Meningitis Caused by an Infected Dermoid Cyst Derived from an Occult Dermal Sinus
}

\author{
Valentina Tono ${ }^{1}$, Sara Bertoletti ${ }^{1}$, Francesca Maltese1, Francesco Canonico ${ }^{2}$, \\ Erik Sganzerla $^{3}$, Carlo Giussani ${ }^{3}$, Maria Luisa Melzi ${ }^{1}$, Andrea Biondi ${ }^{1}$ \\ ${ }^{1}$ Department of Pediatrics, University of Milano-Bicocca, Fondazione MBBM, Monza, Italy \\ ${ }^{2}$ Department of Diagnostic and Interventional Radiology, Ospedale S. Gerardo, Monza, Italy \\ ${ }^{3}$ Department of Neurosurgery, Ospedale S. Gerardo, Monza, Italy \\ Email: tonovalentina@gmail.com
}

Received 20 June 2014; revised 15 July 2014; accepted 5 August 2014

Copyright (C) 2014 by authors and Scientific Research Publishing Inc.

This work is licensed under the Creative Commons Attribution International License (CC BY). http://creativecommons.org/licenses/by/4.0/

(c) (i) Open Access

\begin{abstract}
Congenital dermal sinuses are a rare entity of spinal dysraphism. Most patients have cutaneous markers of their presence, including nevus or port wine stains, dimple, hypertrichosis and subcutaneous lipoma. Inclusion tumors, such as dermoid tumor, are associated to dermal sinus tract; they are congenital, benign and slow-growing lesions of midline. Their clinical relevance is due to the possibility of causing infection, spinal abscess, signs of corde or nerve root compression. Spinal Magnetic Resonance Imaging (MRI) is the diagnostic tool of choice. We present the case of a child with atypical meningitis, resistant to large spectrum antibiotic therapy, caused by an infected dermoid cyst, undiagnosed in the first months of life despite repeated MRI.
\end{abstract}

\section{Keywords}

Dermal Sinus, Meningitis, Dermoid Cyst, Spinal Dysraphism

\section{Introduction}

Congenital dermal sinuses are a rare entity of spinal dysraphism usually located at the lumbar or lumbosacral region [1]. They are cutaneous tracts connecting the surface of the skin with deeper structure of the central nervous system or its coverings [2]. Approximately half of all dermal sinuses have associated dermoids or epidermoids, usually at the termination of the tract [3]. Most patients have cutaneous markers indicating their presence, including nevus or port wine stains, dimple, hypertrichosis, subcutaneous lipoma [4].

How to cite this paper: Tono, V., Bertoletti, S., Maltese, F., Canonico, F., Sganzerla, E., Giussani, C., Melzi, M.L. and Biondi, A. (2014) A Girl with Life Threatening Meningitis Caused by an Infected Dermoid Cyst Derived from an Occult Dermal Sinus. Case Reports in Clinical Medicine, 3, 450-456. http://dx.doi.org/10.4236/crcm.2014.38099 
Although the prevalence of open defects (myelomeningocele, meningocele lipomeningomyelocele, myeloschisis and rachischisis ) is well known, the overall prevalence of closed forms that are clinically significant is less clear, since many of these abnormalities are less obvious or hidden at birth. In fact neural tube defects are among the most common congenital abnormalities that result in significant infant morbidity and mortality, affecting one in every 1000 pregnancies in US and developed countries [5] [6]; occult spinal dysraphisms (OSD) are much less common, in particularspinal dermal sinus tract occurs in approximately one in every 2500 live births [7].

Congenital dermal sinuses are associated with a high risk of cerebrospinal fluid infection, or medullary compression [8]. The clinical presentation and course of the condition vary significantly from severely to asymptomatic throughout life [9]. Although the natural history of OSD is somewhat unpredictable, and efforts at predicting morbidity and mortality have had limited success [10], the overall risk of neurologic compromise increases with time [11]. Early diagnosis and intervention are believed to improve outcome in almost all cases [12].

Management of these children needs multidisciplinary approaches; complete clinical evaluation and appropriate investigations are necessary [13], and MRI is the gold standard imaging modality [14].

While there is consensus for the recognition of a suspicious skin marker and identification of underlying anomalies with prompt radiographic evaluation and neurosurgical referral, the terminology, etiology, radiology and optimal management have been the source of ongoing controversy [14], and follow up indications in children with a normal imaging are not so clear.

Here we describe the case of a 3 years old girl with meningitis, non responding to wide spectrum antibiotics, caused by a dermoid cyst infection resulting from a dermal sinus with a negative early proper evaluation by repeated MRI.

\section{Case Description}

A girl was admitted to our service because of persistent fever of unknown origin. She was the second child of non-consanguineous parents, with no relevant family medical history. The patient was born at term from cesarean for maternal reason, without any complications during delivery. At birth she presented a lumbar-sacral small hairy dimple within a $3 \times 3 \mathrm{~cm}$ port wine stain. The lumbar MRI performed at birth and after 6 months showed a dermal sinus tract that extended at L5 deeply into the subcutaneous tissue reaching the muscle, but not extending intradurally (Figure 1). According to a neurosurgical evaluation, surgery was not suggested.

She grew up uneventfully until 3 years old, when she was admitted to our emergency room with a 9 days history of fever without other symptoms and general good clinical conditions, unresponsive to oral antibiotic therapy

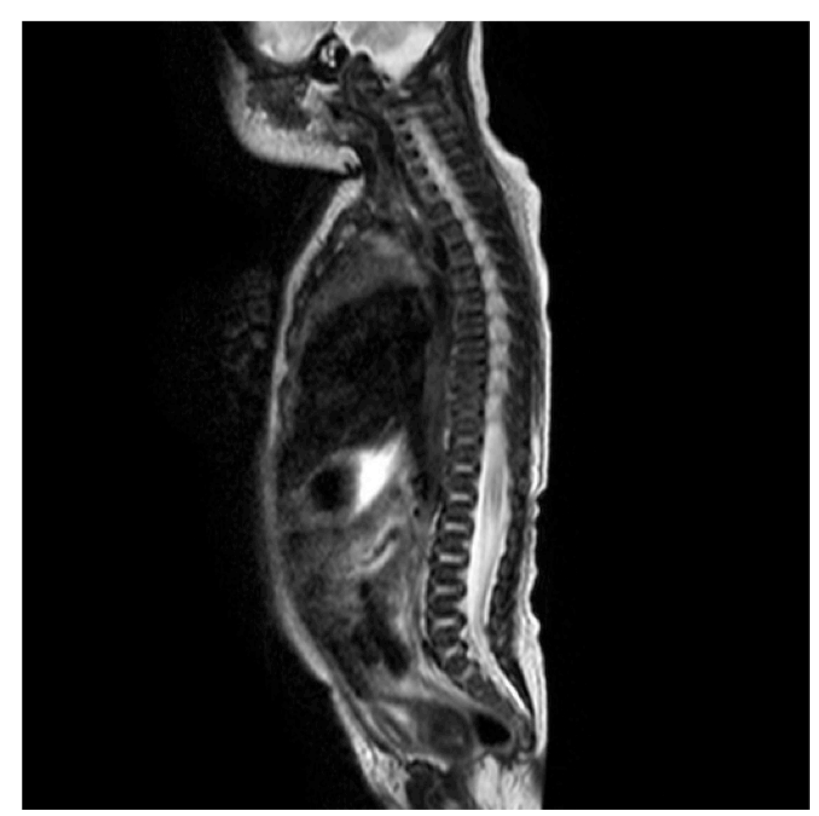

Figure 1. Lumbar MRI at 6 month of life showing a cutaneous tract at L5 not extended intradurally. 
(amoxicillin). Clinical and blood examination were normal, so she was discharged with the suspect of viral infection. After 3 days she was still febrile and she began to complain of backache, lumbar stiffness and pain at the passive and active mobilization of the column, without signs of local infection or inflammation and conserving deambulation. She didn't have neither headache nor vomiting nor signs of neurological involvement. Laboratory data, including a complete blood count and C-reactive protein, were normal. She was admitted to our pediatric department for further investigations. Laboratory studies for EBV, CMV, toxoplasma, borrelia, bordetella, typhus and paratyphus, rickettsia and coxiella, throat swab for adenovirus, antibodies anti-ANA and Mantoux were negative. Chest X-ray did not reveal any abnormal patches and abdomen ultrasound, ECG and echocardiography were also normal. Therefore, empiric intravenous (IV) antibiotic therapy with cefazolin (100 mg/kg/day in 3 doses) was started.

In the following days the patient's clinical conditions worsened: she remained highly febrile and developed fix posture with hyperlordosis and lumbar stiffness, and she was unresponsive to IV skeletal muscle relaxants (diazepam $0.3 \mathrm{mg} / \mathrm{kg}$ ). A lumbar puncture was performed and the cerebrospinal fluid (CSF) examination showed purulent liquid with neutrophil leukocytosis (1100 cells $\left./ \mathrm{mm}^{3}\right)$, hypoglicorrachia (2 $\left.\mathrm{mg} / \mathrm{dl}\right)$ and hyperproteinorrachia $(189 \mathrm{mg} / \mathrm{dl})$. The patient was treated with IV ceftriaxone $(100 \mathrm{mg} / \mathrm{kg} / \mathrm{day})$ and IV dexamethasone $(0.4 \mathrm{mg} / \mathrm{kg}$ 2 times a day). During steroid therapy she became afebrile but persistently suffering and irritable. The CSF culture demonstrated Enterococcus Faecalis (D group), so the current therapy was changed according to antibiogram and IV ampicillin (400 mg/kg/day), linezolid (10 mg/kg per 3 times a day) and gentamicin ( $7.5 \mathrm{mg} / \mathrm{kg} /$ day) were started. Since Enterococcus Faecalis meningitis is very uncommon in immunocompetent patients, Ig and HIV screening were performed and resulted to be negative. There was no clinical improvement under this therapy. For the presence of the dermal sinus and under the suspicion of an external CSF contamination, despite normal previous MRI evaluation, a brain and thoraco-lumbar MRI was performed. The image confirm the tract reaching the muscle, but not extending intradurally (Figure 2). After a comparison with previous imaging, sagittal T1- and T2-weighted sequences performed with and without gadolinium administration showed hypo-isointensity on T2-weighted image, suggestive for a small abscess (Figure 3, Figure 4). Contextually the lumbar puncture showed persistent purulent liquor and Enterococcus Faecalis and Enterovirus were isolated.

In order to evacuate this abscess, unresponsive to medical therapy, the patient underwent a surgical intervention. The lesion was explored with a longitudinal incision extending from L5 to L3 and after dura opening, a large quantity of pus discharged from the subdural space. A dermoid cyst containing sebum and hair was found among the nerve roots, and a complete dissection of the cyst itself was performed. The whole operative field was irrigated with warm saline and gentamicin, the dura was closed and the deep tissue was closed in several layers with absorbable sutures. The CSF culture demonstrated a polymicrobic flora: Proteus and Enterococcus Faecalis and anaerobic flora were detected. After this intervention, the patient became apyretic; neurological status and clinical conditions gradually improved. In the following days white blood cells count and C-reactive protein normalized. No neurological deficit was present after full recovery.

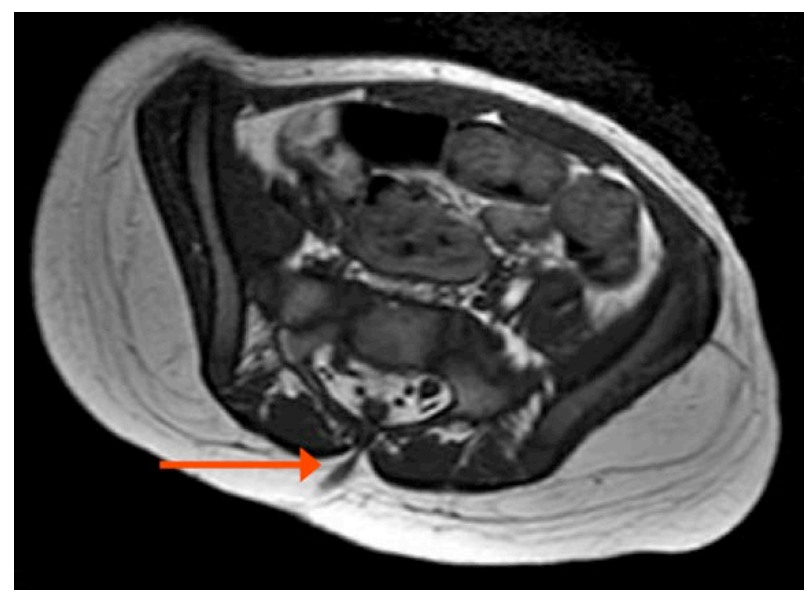

Figure 2. Dermal sinustract that reach the muscular plan, but not extending intradurally. 


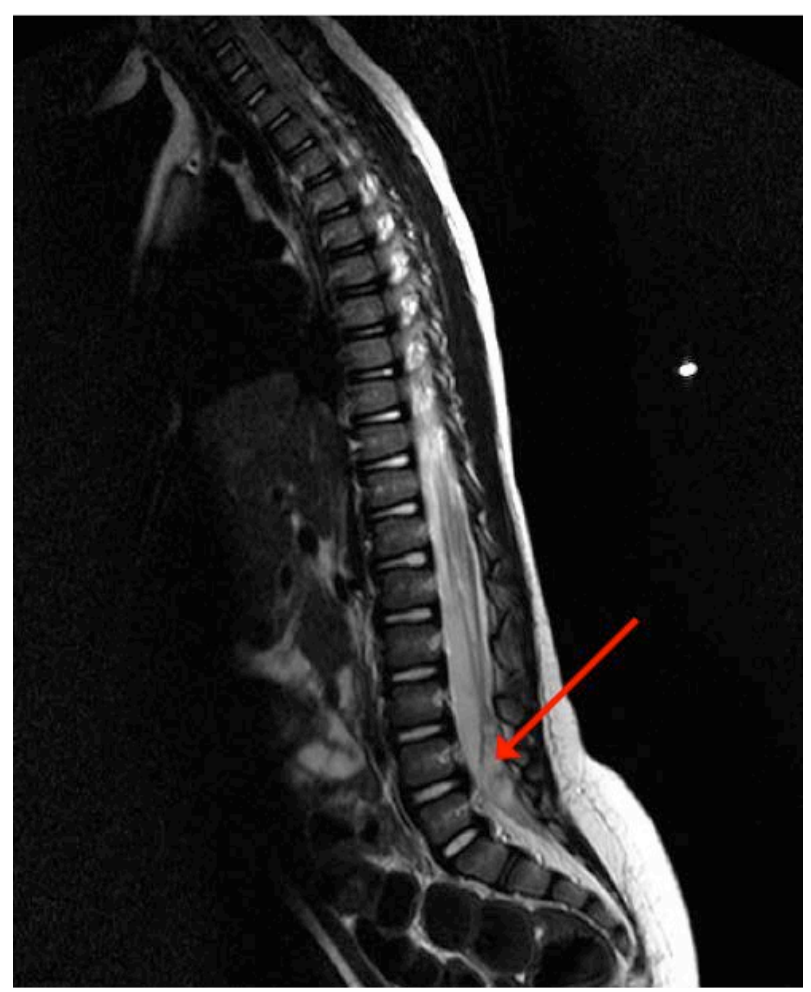

Figure 3. Sagittal magnetic resonance imaging scan showing hypo-isointensity image suggestive for a small abscess (red arrow).

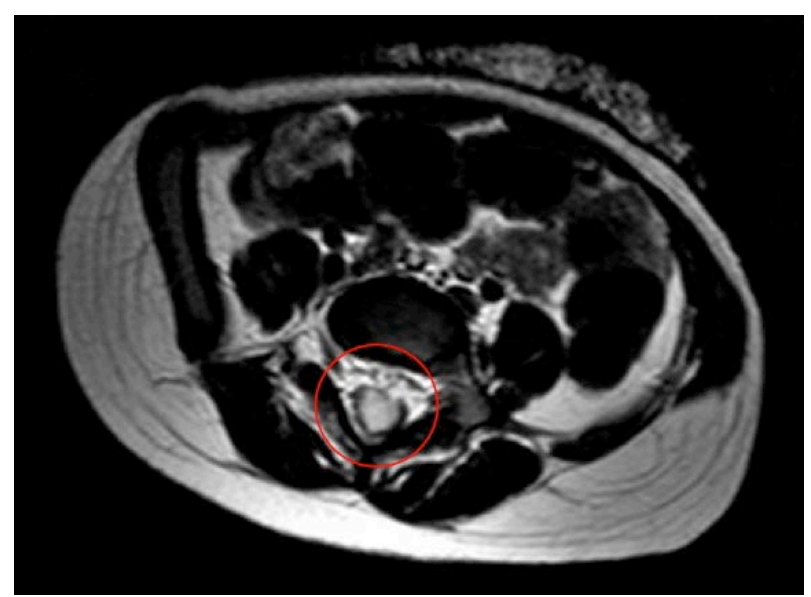

Figure 4. Axial magnetic resonance imaging scan showing hypoisointensity image suggestive for a small abscess (red circle).

Follow-up examination at 24 months revealed normal neurological function; the MRI was normal.

\section{Discussion}

Dermal sinus tracts are rare congenital midline malformations derived from abnormal neurulation. Their presence is often associated with other skin markers of cutaneous dysraphism, such as subcutaneous lipomas, tails, localized hypertrichosis, hyperpigmented or vascular lesions (i.e. port wine stains or hemangiomas), deviation of the gluteal furrow, dimples [11] [15] [16]. Early recognition of these stigmata is important in order to detect underlying spinal anomalies or intraspinal tumors. A combination of two or more congenital midline skin lesions is the 
strongest clue of occult spinal dysraphism [11] [14] [17]. Our patient presented at birth a lumbar-sacral small hairy dimple within a $3 \times 3 \mathrm{~cm}$ port wine stain. If OSD is suspected, the child should be referred for neurosurgical evaluation, preferably by a pediatric neurosurgeon, for complete clinical evaluation and appropriate investigations [13]. In the neonatal period and until approximately 3 months of age spinal ultrasound scan can provide excellent imaging of the terminal spinal cord and offers a sensitive, non-invasive test for suspected spinal dysraphism [18]. Spinal ultrasound can be performed up to the age of 3 months, but it is unreliable as a stand-alone diagnostic tool because it is user-dependent and has a high false-negative rate [9]. MRI is the definitive imaging modality. It is mandatory to explore the entire spine if a cutaneous anomaly or vertebral anomaly suggests the presence of a malformation [14]. In our case lumbar MRI performed at birth and after 6 months showed a dermal sinus tract but not extending intradurally.

Inclusion tumors, such as epidermoid or, more frequently, dermoid cysts are associated to dermal sinus tract in about $43 \%$ of cases [19] [20]. In particular, dermoid cysts accounts for about $20 \%$ of all intramural tumors in the first year of life. They are congenital, benign, slow-growing tumor-like lesions of midline. They are thought to originate from inclusion of the ectoderm during the closure of the neural tube [21]-[24].

Their clinical relevance is due to the possibility of causing infection, spinal abscess or even meningitis. Therefore signs of cord or nerve root compression such as gait disturbance, urine poor flow or other neurological signs of tethered cord can be symptoms of the presence of a dermoid cyst. Our patient presented a meningitis probably localized in the lumbar side (normal blood count and C-reactive protein, no vomiting, no headache) and caused by polymicrobic intestinal flora (Enterococcus Faecalis, Enterovirs, Proteus) resistant to the antibiotic therapy. Under the suspicion of a CSF contamination through the dermal sinus tract we performed a brain and thoraco-lumbar MRI. The comparison with previous imaging showed hypo-isointensity on T2-weighted image, suggestive for a small abscess. The association of dermal sinus tracts with intramedullary abscess through cutaneous fistula is less frequent than meningitis [3] [9]. Rarely, an association between dermal sinus and intramedullary abscess is reported [25]. The diagnosis of intradurally infected dermoid cyst was made during surgery and only the surgical ablation was able to recover the patient. She became apyretic and improved her neurological status and clinical conditions.

In the light of complications associated with dermal sinus (infection and dermoid cyst formation) and the potential for such complications to result in lasting damage, there is general consensus that these lesions should be explored and excised even where symptoms are minimal or absent. In experienced hands the risks of surgery are small and the long term prognosis is excellent [26]. Management of the asymptomatic patient who presents with cutaneous stigmata alone is controversial. Some surgeons advocate a conservative approach, reserving surgery for those who develop symptoms. However, operating only when symptoms develop may not reverse the neurological deficit that has developed. Other advocate surgery if there is a complex tethering element, even if the patient is asymptomatic, as the likelihood of progression is high. However, the decision must be made carefully and in consultation with the parents [27].

In symptomatic patients majority of authors recommend prompt surgical intervention, including the resection of the dermal sinus tract and dermoid cyst and drainage of the intramedullary abscess. Prognosis varies depending on the pre-operative status of the patient [3] [9] [14] [28]. Timing of intervention primarily depends on the clinical condition of the child and the impending risks [13].

Our case gives a good clinical picture of a dermoid tumor associated to a dermal sinus developing a severe meningitis unresponsive to pharmacological treatment. The particularity of the case is that our patient was initially misdiagnosed. MRI examinations performed at an early age (at birth and after 6 months) showed only a dermal sinus tract not extending intradurally, without any signs of intramural tumor. Moreover, while dermoid cyst is reported to be a slow-growing tumor, in our patient it showed a very rapid progression into a symptomatic lesion.

This case report highlights the importance of cutaneous markers detection in the diagnosis of OSD, especially for those patients getting negative result at early MRI imaging. A long-term follow up with MRI, particularly during the fast growing ages of life, such as infancy and puberty, is also suggested for this patient, in order to prevent any potential infective occurrence.

\section{References}

[1] Weprin, B.E. and Oakes, W.J. (2000) Coccygeal Pits. Pediatrics, 105, E69. http://dx.doi.org/10.1542/peds.105.5.e69

[2] Hung, P.C., Wang, H.S., Wu, C.T., Lui, T.N. and Wong, A.M. (2007) Spinal Intramedullary Abscess with an Epider- 
moid Secondary to Dermal Sinus. Pediatric Neurology, 37, 144-147. http://dx.doi.org/10.1016/j.pediatrneurol.2007.04.009

[3] Ackerman, L. and Menezes, A.H. (2003) Spinal Congenital Dermal Sinuses: A 30-Year Experience. Pediatrics, 112, 641-647. http://dx.doi.org/10.1542/peds.112.3.641

[4] Guggisberg, D., Hadj-Rabia, S., Viney, C., Bodemer, C., Brunelle, F., Zerah, M., Pierre-Kahn, A., de Prost, Y. and Hamel-Teillac, D. (2004) Skin Markers of Occult Spinal Dysraphism in Children. Archives of Dermatology, 140, 11091115. Erratum in: Archives of Dermatology, 2005, 141(4), 425. http://dx.doi.org/10.1001/archderm.140.9.1109

[5] Blencowe, H., Cousens, S., Modell, B. and Lawn, J. (2010) Folic Acid to Reduce Neonatal Mortality from Neural Tube Disorders. International Journal of Epidemiology, 10, i110-i121. http://dx.doi.org/10.1093/ije/dyq028

[6] Williams, L.J., Rasmussen, S.A., Flores, A., Kirby, R.S. and Edmonds, L.D. (2005) Decline in the Prevalence of Spina Bifida and Anencephaly by Race/Ethnicity: 1995-2002. Pediatrics, 116, 580-586. http://dx.doi.org/10.1542/peds.2005-0592

[7] Radmanesh, F., Nejat, F. and El Khashab, M. (2010) Dermal Sinus Tract of the Spine. Child's Nervous System, 26, 349-357. http://dx.doi.org/10.1007/s00381-009-0962-z

[8] Chen, C.Y., Lin, K.L., Wang, H.S. and Lui, T.N. (1999) Dermoid Cyst with Dermal Sinus Tract Complicated with Spinal Subdural Abscess. Pediatric Neurology, 20, 157-160. Erratum in: Pediatric Neurology, 1999, 21(1), 511. http://dx.doi.org/10.1016/S0887-8994(98)00126-X

[9] Nicola, Z., Antonio, C. and De Tommasi, A. (2014) Cervical Dermal Sinus Complicated with Intramedullary Abscess in a Child: Case Report and Review of Literature. European Spine Journal, 23, 192-196. http://dx.doi.org/10.1007/s00586-013-2930-2

[10] Ben-Sira, L., Garel, C., Malinger, G. and Constantini, S. (2013) Prenatal Diagnosis of Spinal Dysraphism. Child's Nervous System, 29, 1541-1552. http://dx.doi.org/10.1007/s00381-013-2178-5

[11] Zywicke, H.A. and Rozzelle, C.J. (2011) Sacral Dimples. Pediatrics in Review, 32, 109-114. http://dx.doi.org/10.1542/pir.32-3-109

[12] Soonawala, N., Overweg-Plandsoen, W.C.G. and Brouwer, O.F. (1999) Early Clinical Signs and Symptoms in Occult Spinal Dysraphism: A Retrospective Case Study of 47 Patients. Clinical Neurology and Neurosurgery, 101, 11-14. http://dx.doi.org/10.1016/S0303-8467(98)00073-0

[13] Venkataramana, N.K. (2011) Spinal Dysraphism. Journal of Pediatric Neurosciences, 6, 31-40. http://dx.doi.org/10.4103/1817-1745.85707

[14] Valentini, L.G., Selvaggio, G., Erbetta, A., Cordella, R., Pecoraro, M.G., Bova, S., Boni, E., Beretta, E. and Furlanetto, M. (2013) Occult Spinal Dysraphism: Lessons Learned by Retrospective Analysis of 149 Surgical Cases about Natural History, Surgical Indications, Urodynamic Testing, and Intraoperative Neurophysiological Monitoring. Child's Nervous System, 29, 1657-1669. http://dx.doi.org/10.1007/s00381-013-2186-5

[15] Tavafoghi, V., Ghandchi, A., Hambrick, G.W. and Udverhelyi, G.B. (1978) Cutaneous Signs of Spinal Dysraphism. JAMA Dermatology, 114, 573-577. http://dx.doi.org/10.1001/archderm.1978.01640160051015

[16] McAtee-Smith, J., Hebert, A.A., Rapini, R.P. and Goldberg, N.S. (1994) Skin Lesions of Spinal Axis and Spinal Dysraphism: Fifteen Cases and a Review of the Literature. JAMA Pediatrics, 148, 740-748. http://dx.doi.org/10.1001/archpedi.1994.02170070078015

[17] Assaad, A., Mansy, A., Kotb, M. and Hafez, M. (1989) Spinal Dysraphism: Experience with 250 Cases Operated upon. Child's Nervous System, 5, 324-329. http://dx.doi.org/10.1007/BF00274523

[18] Thompson, D.N. (2010) Spinal Dysraphic Anomalies; Classification, Presentation and Management. Paediatrics and Child Health, 20, 397-403. http://dx.doi.org/10.1016/j.paed.2010.03.011

[19] Al Barbarawi, M., Khriesat, W., Qudsieh, H. and Loai, A.A. (2009) Management of Intramedullary Spinal Cord Abscess: Experience with Four Cases, Pathophysiology and Outcomes. European Spine Journal, 18, 710-717. http://dx.doi.org/10.1007/s00586-009-0885-0

[20] Morimoto, K., Takemoto, O., Nakamura, H. and Takeuchi, M. (2003) Spinal Dermal Sinus Associated with Intramedullary Abscess and Dermoid. Pediatric Neurosurgery, 39, 225-226. http://dx.doi.org/10.1159/000072478

[21] Roux, A., Mercier, C., Larbrisseau, A., Dube, L.J., Dupuis, C. and Del Carpio, R. (1992) Intramedullary Epidermoid Cyst of the Spinal Cord. Case Report. Journal of Neurosurgery, 76, 528-533. http://dx.doi.org/10.3171/jns.1992.76.3.0528

[22] Tekkok, I.H., Palaoglu, S., Erbengi, A. and Onol, B. (1992) Intramedullary Epidermoid Cyst of the Cervical Cord Associated with an Extraspinal Neuroenteric Cyst: Case Report. Neurosurgery, 31, 121-125.

[23] Agarwal, A., Bhake, A. and Kakani, A. (2011) Cervical Intramedullary Epidermoid Cyst with Liquid Contents. Asian Spine Journal, 5, 59-63. http://dx.doi.org/10.4184/asj.2011.5.1.59 
[24] Shikata, J., Yamamuro, T., Mikawa, Y. and Kotoura, Y. (1988) Intraspinal Epidermoid and Dermoid Cysts: Surgical Results of Seven Cases. Archives of Orthopaedic and Traumatic Surgery, 107, 105-109. http://dx.doi.org/10.1007/BF00454496

[25] Morandi, X., Mercier, P., Fournier, H.D. and Brassier, G. (1999) Dermal Sinus and Intramedullary Spinal Cord Abscess. Report of Two Cases and Review of the Literature. Child’s Nervous System, 15, 202-206. http://dx.doi.org/10.1007/s003810050370

[26] Thompson, D.N. (2013) Spinal Inclusion Cysts. Child’s Nervous System, 29, 1647-1655. http://dx.doi.org/10.1007/s00381-013-2147-z

[27] Mankahla, N. and Figaji, A. (2014) Occult Spinal Dysraphism. South African Medical Journal, $104,316$. http://dx.doi.org/10.7196/samj.8196

[28] Vadivelu, S., Desai, S.K., Illner, A., Luerssen, T.G. and Jea, A. (2014) Infected Lumbar Dermoid Cyst Mimicking Intramedullary Spinal Cord Tumor: Observations and Outcomes. Journal of Pediatric Neurosciences, 9, 21-26. http://dx.doi.org/10.4103/1817-1745.131475 
Scientific Research Publishing (SCIRP) is one of the largest Open Access journal publishers. It is currently publishing more than 200 open access, online, peer-reviewed journals covering a wide range of academic disciplines. SCIRP serves the worldwide academic communities and contributes to the progress and application of science with its publication.

Other selected journals from SCIRP are listed as below. Submit your manuscript to us via either submit@scirp.org or Online Submission Portal.
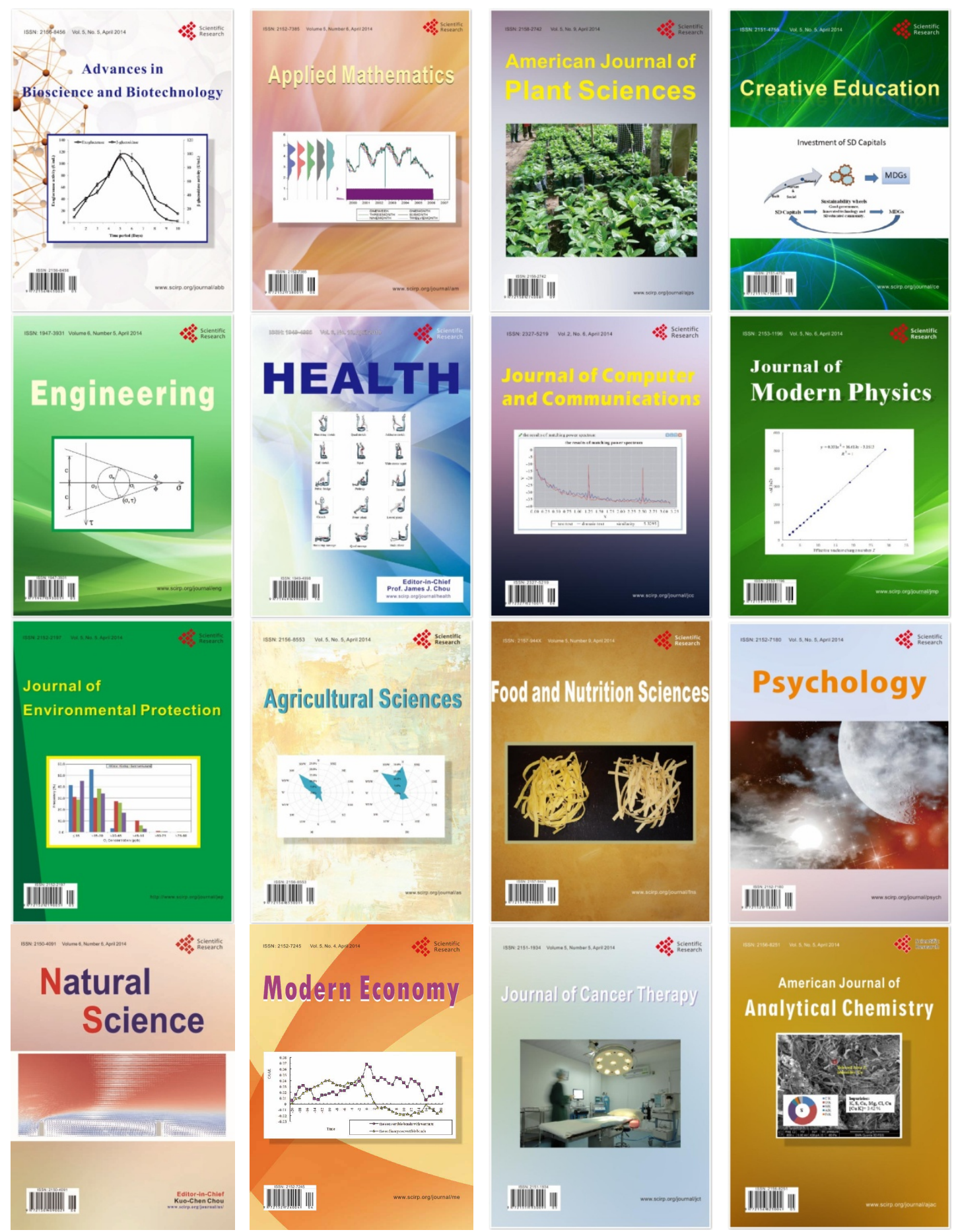